\title{
ВЛИЯНИЕ СТВОЛОВОЙ ГНИЛИ НА ФЕНОЛЬНЫЕ СОЕДИНЕНИЯ В ЛИСТЬЯХ ТОПОЛЯ БАЛЬЗАМИЧЕСКОГО (РОРULUS BALSAMIFERA L.) В УСЛОВИЯХ УРБАНИЗАЦИИ
}

\author{
(C) Е.В. Колтунов
}

Ботанический сад УрО РАН, ул. 8 марта, 202а, Екатеринбуре, 620144, (Россия), e-mail: evg_koltunov@mail.ru

Тополь бальзамический служит важным компонентом озеленения городской среды. Он отличается высокой скоростью роста и устойчивостью к негативным факторам среды, но в условиях урбанизации интенсивно поражается болезнями, особенно стволовыми гнилями. Биохимический состав различных компонентов тополя изучен в основном у почек [1-4]. У листьев он менее исследован [5-7]. Поэтому изучение влияния стволовой гнили на фенольные соединения в листьях тополя в условиях урбанизации и было основной целью исследования. Биохимический состав листьев изучали методом ВЭЖХ. Хроматография экстрактов из листьев выявила 88 соединений, из них идентифицировано 22. Преобладающей тенденцией в листьях пораженных растений была активизация их синтеза (у $45.46 \%$ ). В их составе преобладали флавоноиды (50\%). Это следствие реакции на оксидативный стресс. У 27.27\% соединений наблюдалось ингибирование синтеза фенольных соединений. У $27.27 \%$ соединений их количество не изменялось. Различий в составе химических соединений в листьях контрольных и пораженных гнилями растений не наблюдалось. В целом, реакция различных видов древесных растений на стволовую гниль и аэротехногенное загрязнение отличается. Это обусловлено как видоспецифичностью отклика, так и разным уровнем резистентности и толерантности различных видов и разными механизмами адаптации к этим факторам. Учитывая, что у разных видов растений существуют разные стратегии отношения к воздействию факторов среды, не исключено, что сходный механизм существует и у разных видов древостоев, пораженных гнилями.

Ключевые слова: ВЭЖХ, стволовая гниль, тополь бальзамический, листья, фенольные соединения.

\section{Введение}

Тополь бальзамический служит важным компонентом озеленения городской среды. Его особенностью является высокая скорость роста и устойчивость к неблагоприятным факторам среды. В условиях урбанизации он поражается многими болезнями. Одна из основных - стволовая гниль. Биохимический состав различных компонентов этого древесного растения изучен достаточно широко, но это относится в основном к почкам тополя [1-4]. Биохимический состав листьев тополя бальзамического менее изучен [5-7]. К настоящему времени результаты исследований различных видов древесных растений остаются противоречивыми. Аэротехногенное загрязнение сосны обыкновенной (Pinus sylvestris L.) сопровождается разнонаправленными изменениями активности синтеза фенольных соединений в хвое $[8,9]$. В условиях городской среды, вблизи автомагистралей, преобладает ингибирование активности синтеза фенольных соединений [9]. При этом у флавоноидов заметно доминировало увеличение активности синтеза этих соединений в хвое. В других условиях в хвое сосны в урбанизированной среде преобладало увеличение активности их синтеза [8]. У березы повислой (Betula pendula Roth.) в условиях антропогенного воздействия стволовая гниль сопровождалась одинаковым уровнем как активизации, так и ингибирования синтеза флавоноидов (по 35.9\%) в листьях [10]. У идентифицированных соединений преобладало увеличение активности их синтеза [10]. Интенсивное аэротехногенное загрязнение березы повислой сопровождалось доминированием ингибирования активности синтеза химических соедине-

Колтунов Евгений Владимирович - доктор биологических наук, профессор, ведущий научный сотрудник, e-mail: evg_koltunov@mail.ru ний (при тотальном анализе), тогда как в группе идентифицированных соединений у $80 \%$ из них

*Данная статья имеет электронный дополнительный материал (приложение), который доступен читателям на сайте журнала. DOI: 10.14258/jcprm.2021028246s 
наблюдалось ингибирование активности синтеза химических соединений [11]. Наоборот, в условиях умеренного техногенного загрязнения доминировало увеличение активности синтеза химических соединений в листьях [11]. Ряд авторов сообщает о двухфазном характере реакции фенольных соединений в листьях на аэротехногенное загрязнение, когда в импактной зоне преобладает ингибирование синтеза этих соединений, а в зоне умеренного техногенного воздействия доминировало возрастание интенсивности синтеза фенольных соединений [12]. Имеются данные и о возможности индукции резистентности к гнилевым болезням растений с помощью ряда химических соединений [13]. Таким образом, в целом, есть достаточно оснований предполагать, что разные виды древесных растений, пораженных стволовыми гнилями, в условиях урбанизации по-разному реагируют на воздействие этих факторов. В связи с этим изучение влияния стволовой гнили в условиях урбанизации на фенольные соединения в листьях тополя бальзамического и было основной целью исследований.

\section{Экспериментальная часть}

Состав фенольных и других соединений в листьях тополя бальзамического исследовали методом градиентной жидкостной хроматографии. Сбор листьев для ВЭЖХ проводился в городских лесопосадках г. Екатеринбурга вблизи автомагистралей 6 августа. Перед отбором проб определяли наличие или отсутствие пораженности дерева стволовыми гнилями и стадию развития болезни с помощью взятия кернов из ствола. Взятие каждой пробы листьев осуществлялось от нескольких деревьев одинакового диаметра. Затем пробы смешивались. Контрольные пробы отбирали от здоровых деревьев, не пораженных гнилевыми и другими болезнями. Сразу после сбора листья высушивали при комнатной температуре, затем размалывали. Навеску с 2 г размолотых листьев смешивали с 20 мл 95\% этанола. Экстракцию фенольных соединений из листьев проводили $95 \%$ этиловым спиртом в водяной бане с обратным холодильником в течение 30 мин при кипении раствора. Затем суспензию центрифугировали при $10000 \mathrm{~g}$ в течение 10 мин. Супернатант фильтровали через шприцевый фильтр с диаметром пор 0.2 мкм. Хроматографию проводили на жидкостном хроматографе Shimadzu LC-20 со спектрофотометрическим УФ детектором. Детектирование элюента осуществляли одновременно на двух полосах поглощения: $\lambda_{360}$ и $\lambda_{254}$ нм на колонке PerfectSil Target ODS-35 мкм с обращенной фазой, затем вычислялось спектральное отношение параметров абсорбции $\left(\lambda_{360} / \lambda_{254}\right)$. Градиентное элюирование проводилось в диапазоне $10-50 \%$ со скоростью 1 мл/мин при температуре $40{ }^{\circ} \mathrm{C}$. Элюент А - ацетонитрил-0.05 М фосфатный буферный раствор ( $\mathrm{pH}=3.0)$; элюент $\mathrm{B}$ - ацетонитрил- дистиллированная вода $(9: 1)$. Продолжительность хроматографии - 50 мин. Из них от 0 до 30 мин проводилось градиентное элюирование в диапазоне 10-50\%, затем в течение 20 мин - при концентрации 50\%. Для идентификации фенольных соединений использовали 24 вещества-свидетеля фирмы: Fluka, Sigma, Aldrich. Идентификацию хроматографических пиков проводили по TR (время удерживания) и спектральному соотношению параметров абсорбции. Количественное определение химических соединений проводили с использованием метода градуировки по внешнему стандарту. Для этого по каждому химическому соединению готовили серии разведений стандартных образцов и после проведения хроматографии по описанной выше методике строили градуировочные графики. Содержание химических соединений определяли в миллиграммах на 1 г СВ (сухого вещества). Статистическую обработку полученных данных проводили с помощью Т-критерия Стьюдента [14].

\section{Обсуждение результатов}

В целом хроматографический анализ выявил в листьях тополя бальзамического 88 химических соединений (рис. 1). Из них было идентифицировано 22 соединения. Это: аскорбиновая кислота, арбутин, галловая кислота, салицин, гидрохинон, кофейная кислота, 4-кофеоилхинная кислота, салидрозид, рутин, феруловая кислота, изокверцетин, изокверцетрин, дигидрокверцетин, авикулярин, феникулин, мирицетин, лютеолин, кверцетин, изорамнетин, апигенин, кемпферол, акацетин (рис. 1, табл.).

Как показали результаты, часть химических соединений была ранее идентифицирована в почках тополя другими авторами, некоторые соединения нам не удалось обнаружить в публикациях других авторов. В целом полученные нами результаты демонстрируют значительно большее количество различных химических соединений, чем в публикациях других авторов $[1,5]$.

Сравнительный анализ показал, что в листьях тополя со стволовой гнилью, в целом, изменение активности синтеза соединений было различного характера. Преобладающей тенденцией у идентифицированных соединений было увеличение активности их синтеза (у 45.46\%) (рис. 2). У 27.27\% соединений наблюдалось 
снижение активности их синтеза в листьях. У такого же количества химических соединений количественные различия были статистически недостоверны (рис. 2). Из состава идентифицированных соединений наиболее значительно активность синтеза фенольных соединений возрастала у авикулярина, кверцетина, изокверцитрина, мирицетина, рутина, лютеолина (рис. 1, табл.). Качественных различий в составе химических соединений в листьях контрольных и пораженных стволовой гнилью химических соединений не наблюдалось. Нами были выявлены только количественные различия (рис. 1-3; табл.).

Как показали результаты, в составе соединений, активность синтеза которых возрастала в листьях тополей со стволовой гнилью, значительно преобладали флавоноиды (50\%), (рис. 3, табл.). Наиболее интенсивное возрастание активности синтеза флавоноидов в листьях выявлено у авикулярина, изокверцитрина, кверцетина, рутина, мирицетина. Ингибирование синтеза из всех идентифицированных флавоноидов выявлено лишь у 25\%, это изокверцетин, изорамнетин, дигидрокверцетин (табл., рис. 3). Отсутствие изменений в активности синтеза было выявлено у 25\% флавоноидов (рис. 3) - апигенин, феникулин, кемпферол. Учитывая, что это минорные компоненты, их роль несущественна (табл.).

Из состава фенолгликозидов возрастание активности синтеза было отмечено только у салидрозида. У арбутина и салицина активность синтеза в листьях зараженных деревьев снижалась (табл.). Из других групп соединений у 50\% гидроксикоричных кислот активность синтеза заметно снижалась, у $33.3 \%$-возрастала, у такого же количества - снижалась (табл.).

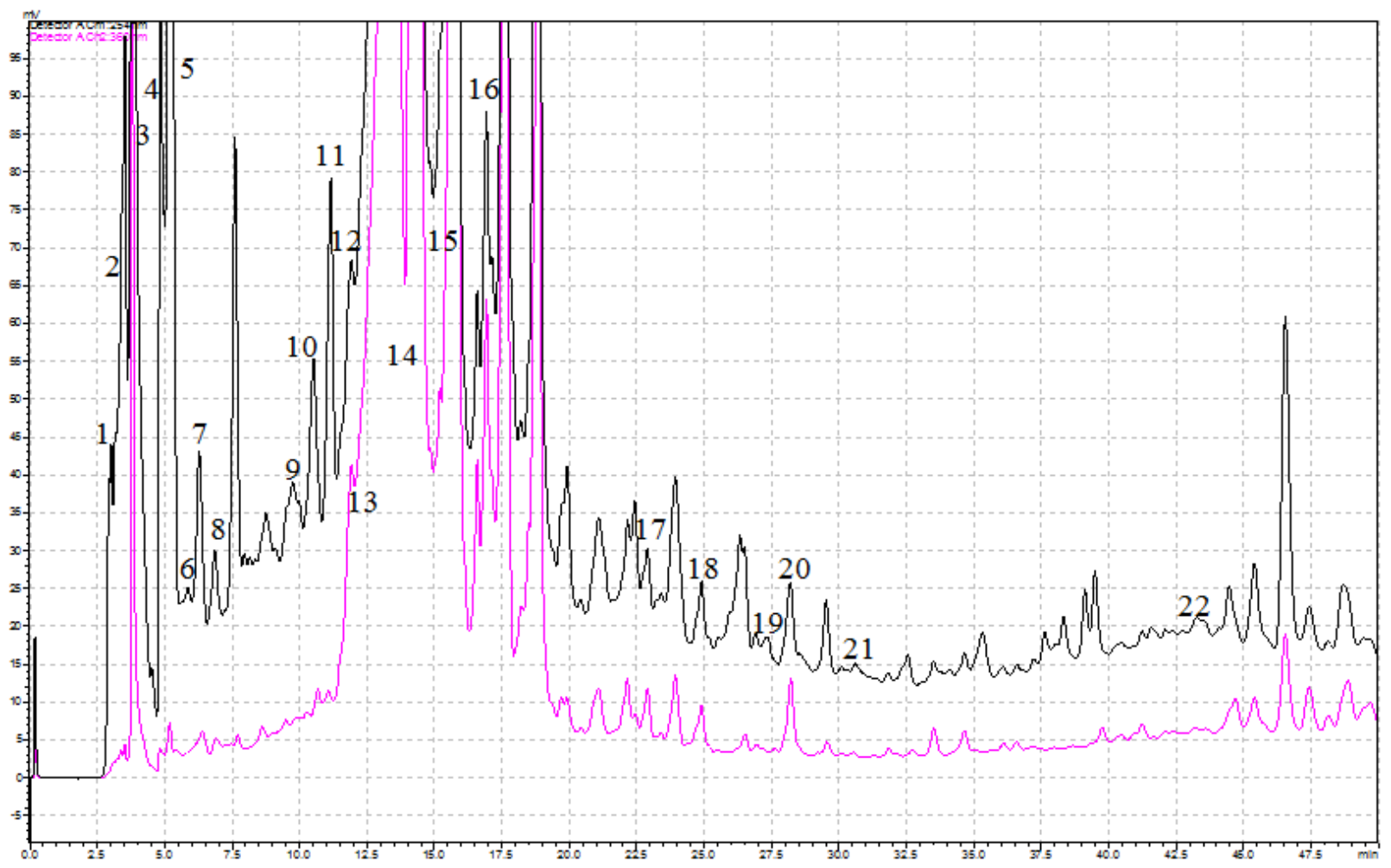

Рис. 1. Хроматограмма спиртового экстракта листьев тополя бальзамического. Контроль. По горизонтали: $\operatorname{Tr}$ (время удерживания (мин)), по вертикали: абсорбция, $\mathrm{mV}$. Условные обозначения: 1 - аскорбиновая кислота; 2 - арбутин; 3 - галловая кислота; 4 - салицин; 5 - гидрохинон; 6 - кофейная кислота; 7 - 4-кофеоилхинная кислота; 8 - салидрозид; 9 - рутин; 10 - феруловая кислота; 11 - изокверцитрин; 12 - изокверцетин; 13 - авикулярин; 14 -дигидрокверцетин; 15 - феникулин; 16 - мирицетин; 17 - лютеолин; 18 - кверцетин;19 - изорамнетин; 20 - апигенин; 21 - кемпферол; 22 - акацетин 


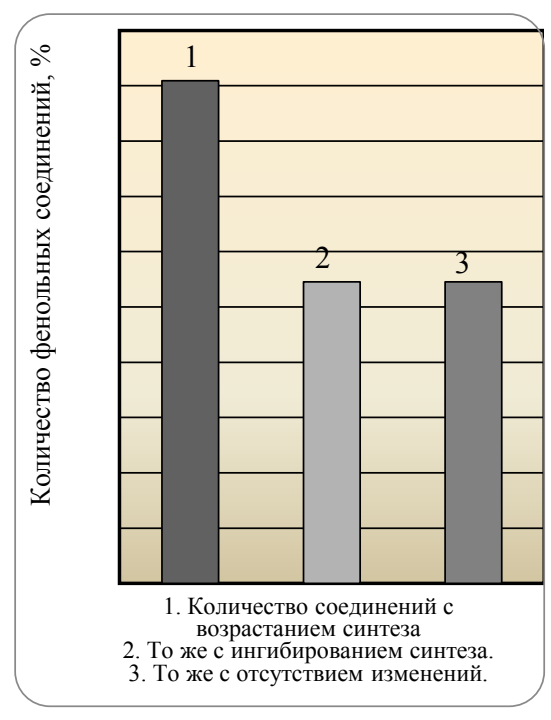

Рис. 2. Влияние стволовой гнили на активность синтеза идентифицированных соединений листьев тополя бальзамического со стволовой гнилью

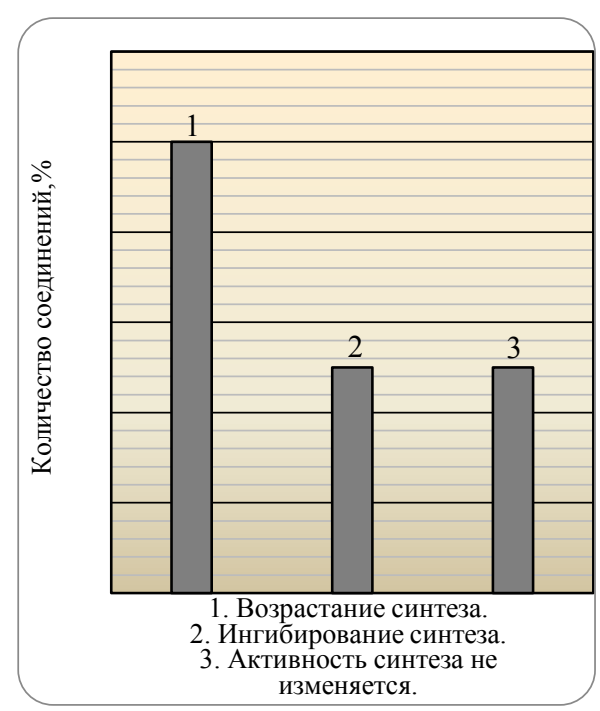

Рис. 3. Влияние стволовой гнили на активность синтеза флавоноидов в листьях тополя бальзамического в условиях урбанизации

Влияние стволовой гнили на активность синтеза идентифицированных химических соединений в листьях тополя бальзамического (Populus balsamifera L.) в условиях урбанизации

\begin{tabular}{|c|c|c|c|c|c|}
\hline Наименование соединения & $\begin{array}{c}\text { Контроль. } \\
\text { Содержание хими- } \\
\text { ческого соединения } \\
(\text { мг/1 г СB) M } \pm \text { SD }\end{array}$ & $\begin{array}{c}\text { Стволовая гниль } \\
\text { Содержание хими- } \\
\text { ческого соединения } \\
\text { (мг/1г CB) M } \pm \mathrm{SD}\end{array}$ & $\begin{array}{c}\text { TSt. } \\
\text { Критерий } \\
\text { Стьюдента }\end{array}$ & $\mathrm{P}$ & $\begin{array}{c}\text { Изменение } \\
\text { содержания } \\
\text { соединений } \\
\text { (в \% к контр.) }\end{array}$ \\
\hline Аскорбиновая кислота & $3.10 \pm 0.29$ & $2.21 \pm 0.14$ & 26.09 & 0.0010 & -28.71 \\
\hline Арбутин & $5.21 \pm 0.24$ & $1.66 \pm 0.122$ & 26.09 & 0.0001 & -68.14 \\
\hline Галловая кислота & $0.79 \pm 0.089$ & $0.64 \pm 0.050$ & 2.46 & 0.050 & -18.99 \\
\hline Салицин & $4.50 \pm 0.351$ & $3.53 \pm 0.352$ & 3.67 & 0.0010 & -21.55 \\
\hline Салидрозид & $0.061 \pm 0.0055$ & $0.071 \pm 0.004$ & 3.290 & 0.0016 & +16.39 \\
\hline 4-кофеоилхинная кислота & $2.40 \pm 0.096$ & $2.71 \pm 0.095$ & 3.69 & 0.0100 & +12.92 \\
\hline Гидрохинон & $5.22 \pm 0.412$ & $6.11 \pm 0.452$ & 3.71 & 0.014 & +17.62 \\
\hline Рутин & $0.47 \pm 0.0408$ & $0.65 \pm 0.0457$ & 5.36 & 0.0018 & +39.20 \\
\hline Дигидрокверцетин* & $2.17 \pm 0.089$ & $2.097 \pm 0.097$ & 1.33 & 0.3411 & -3.31 \\
\hline Изокверцетин & $4.01 \pm 0.223$ & $2.55 \pm 0.147$ & 11.08 & 0.0000 & -36.25 \\
\hline Изокверцитрин & $0.42 \pm 0.0182$ & $0.64 \pm 0.0294$ & 13.279 & 0.0000 & +52.38 \\
\hline Авикулярин & $1.07 \pm 0.0761$ & $1.8 \pm 0.0983$ & 12.383 & 0.0000 & +68.22 \\
\hline Мирицетин & $2.75 \pm 0.182$ & $4.69 \pm 0.357$ & 7.15 & 0.0004 & +49.82 \\
\hline Лютеолин & $0.05 \pm 0.0059$ & $0.071 \pm 0.005$ & 6.110 & 0.0008 & +42.0 \\
\hline Кверцетин & $4.02 \pm 0.399$ & $6.31 \pm 0.529$ & 6.841 & 0.0005 & +57.21 \\
\hline Апигенин* & $1.79 \pm 0.204$ & $1.81 \pm 0.284$ & 1.042 & 0.3370 & +1.1 \\
\hline Кемпферол* & $0.27 \pm 0.0183$ & $0.28 \pm 0.0294$ & 0.570 & 0.5850 & +3.70 \\
\hline Феникулин* & $0.32 \pm 0.0294$ & $0.31 \pm 0.0263$ & 0.379 & 0.717 & -3.13 \\
\hline Акацетин & $1.14 \pm 0.050$ & $1.24 \pm 0.051$ & 2.380 & 0.0500 & +8.13 \\
\hline Изорамнетин & $0.09 \pm 0.023$ & $0.044 \pm 0.028$ & 3.90 & 0.0078 & -51.12 \\
\hline Кофейная кислота* & $0.003 \pm 0.000$ & $0.003 \pm 0.000$ & 0.4804 & 0.6479 & 0.00 \\
\hline Феруловая кислота* & $3.301 \pm 0.147$ & $3.186 \pm 1.701$ & 1.347 & 0.2270 & -3.460 \\
\hline
\end{tabular}

* - различия статистически недостоверны.

Как известно, единое мнение о влиянии стволовых гнилей на фенольные соединения в листьях древесных растений в условиях урбанизации отсутствует [8-11]. Поэтому проблема до настоящего времени остается дискуссионной. Как показали полученные нами результаты, в условиях интенсивного аэротехногенного воздействия на лесопосадки тополя бальзамического, пораженного стволовой гнилью (вблизи го- 
родских автомагистралей с интенсивным потоком автотранспорта), тенденция к активизации синтеза фенольных соединений в листьях тополя бальзамического доминировала. Сходная тенденция была выявлена ранее у березы повислой, пораженной стволовой гнилью (Betula pendula Roth.). С другой стороны, у сосны обыкновенной (Pinus sylvestris L.) в условиях аэротехногенного загрязнения основной тенденцией было снижение активности синтеза фенольных соединений [8-10]. Вероятно, это обусловлено тем, что как заражение стволовыми гнилями, так и аэротехногенное загрязнение в условиях урбанизации сопровождается развитием оксидативного стресса у древесных растений. Это сопровождается генерацией в клетках активных форм кислорода $[13,15,16]$ и активизацией биохимических систем антиоксидантной защиты. В их состав входят как ферментные системы (каталаза, пероксидаза, супероксидисмутаза), так и низкомолекулярные соединения: флавоноиды, гидроксикоричные кислоты и другие [15-18]. Состав соединений, активность синтеза которых возрастает, у разных видов древесных растений имеет определенные различия. Но у тополя бальзамического, как и у березы повислой, в листьях которых активность синтеза фенольных соединений заметно возрастала как при воздействии аэротехногенного загрязнения, так и у пораженных стволовыми гнилями древостоев, доминирующей группой были флавоноиды. Это обусловлено их антиоксидантной активностью. Учитывая, что у ряда ряда фенольных соединений тополя выявлена фунгицидная и антимикробная активность, этот механизм также выполняет определенную роль в активизации синтеза этих соединений в пораженных стволовыми гнилями древесных растениях [19, 20].

\section{Bblводы}

Изучено влияние стволовой гнили у тополя бальзамического на активность синтеза фенольных и других химических соединений в листьях. Показано, что доминирующей тенденцией у идентифицированных соединений было увеличение активности их синтеза (у 45.46\%), у 27.27\% соединений наблюдалось снижение активности их синтеза в листьях, у такого же количества химических соединений количественные различия были статистически недостоверны. В составе флавоноидов у 50\% активность синтеза заметно возрастала, у 25\% - снижалась, у такого же количества - не изменялась. Такой характер изменений обусловлен антиоксидантной активностью флавоноидов и других соединений.

Хроматографический анализ листьев тополя бальзамического выявил 88 различных химических соединений, из которых было идентифицировано 22 соединения. В их составе доминировали: арбутин, салицин, аскорбиновая кислота, гидрохинон, изокверцетин, кверцетин, феруловая кислота. В целом полученные нами результаты демонстрируют значительно большее количество различных химических соединений в листьях, чем в публикациях других авторов.

Полученные нами результаты позволяют предположить, что в условиях урбанизированной городской среды поражение тополя бальзамического стволовой гнилью сопровождается разнонаправленными реакциями, но при этом заметно преобладает активизация синтеза фенольных соединений в листьях. Учитывая антиоксидантную активность многих из них, это является проявлением комплексной реакции тополя бальзамического на оксидативный стресс.

Сравнительный анализ реакции других видов древесных растений и тополя бальзамического на стволовую гниль демонстрирует, что реакция различных видов древесных растений на этот фактор отличается. Это, вероятно, обусловлено, как ее видоспецифичностью, так и разным уровнем резистентности и толерантности различных видов древесных растений и разными механизмами адаптации к воздействию этих факторов. Кроме того, у разных групп растений, возможно, существуют разные стратегии отношения к воздействию этого фактора и разные уровни, характер и направление реакций.

\section{Список литературь}

1. Isaeva E., Lozhkina G., Ryazanova T. A study of the alcohol extract from balsam poplar buds // Russian Journal of Bioorganic Chemistry. 2010. Vol. 36 (7). Pp. 929-933. DOI: 10.1134/S1068162010070228.

2. Isidorov V.A., Vinogorova V.T. GC-MS analyses of compounds extracted from buds of Populus balsamifera and Populus nigra // Z. Naturforsch. 2003. Pp. 355-360. DOI: 10.1515/znc-2003-5-612.

3. Исаева Е.В., Ложкина Г.А., Рязанова Т.В., Морозов С.В., Черняк Е.И. Флавоноиды почек тополя бальзамического (Populus balsamifera L.), произрастающего в Красноярске. 1. Флавоноиды этилацетатного экстракта почек тополя бальзамического // Химия растительного сырья. 2008. №2. С. 47-53. 
4. Жанымханова П.Ж. Фармакогностическое изучение лекарственного растительного сырья почек тополя бальзамического (Populus balsamifera L.), произрастающего на территории Казахстана и его стандартизация // Вестник КГМА им. И.К. Ахунбаева. 2015. №2. С. 159-162.

5. Isaeva E.V., Rjazanova T.V., Gavrilova L.V. Gruppovoj himicheskij sostav list'ev topolja // Sciences of Europe. 2016. Vol. 1. N8. Pp. 116-121.

6. Исаева Е.В., Рязанова Т.В., Грак О.А. Закономерности выделения и фракционирования экстрактивных веществ листьев тополя // Новые достижения в химии и химической технологии растительного сырья: материалы VII Всерос. конф. (24-28 апреля 2017 г.). Барнаул, 2017. С. 300-302.

7. Сосипатрова А.А., Осипов В.И., Демина Н.Б., Быков В.А. Биологически активные вещества сухого экстракта листьев березы: идентификация и количественное определение фенольных соединений методом ВЭЖХ // Вопросы биологической, медицинской и фармацевтической химии. 2011. №3. С. 23-29.

8. Шавнин С.А., Колтунов Е.В., Яковлева М.И. Влияние урбанизации на состав и содержание фенольных соединений в хвое сосны обыкновенной (Pinus sylvestris L.) // Современные проблемы науки и образования. 2014. № 6. URL: https://www.science-education.ru/ru/article/view?id=17151.

9. Колтунов Е.В. Влияние аэротехногенного загрязнения на состав и содержание фенольных соединений в хвое сосны обыкновенной (Pinus sylvestris L.) в условиях урбанизации // Успехи современного естествознания. 2019. №9. С. 19-25.

10. Колтунов Е.В., Яковлева М.И. Влияние стволовой гнили на состав и содержание фенольных соединений в листьях березы повислой (Betula pendula Roth.) в лесах Зауралья в условиях антропогенного воздействия // Современные проблемы науки и образования. 2015. №5. URL: https://www.science-education.ru/ru/article/view?id=21797.

11. Шавнин С.А., Колтунов Е.В., Яковлева М.И. Влияние техногенного загрязнения на содержание фенольных соединений в листьях березы повислой (Betula pendula Roth.) в условиях урбанизации // Современные проблемы науки и образования. 2014. №2. С. 520.

12. Артёмкина Н.А. Низкомолекулярные фенольные соединения древесной зелени ели европейской (Picea abies L.). автореф. дис. ... канд. хим. наук. СПб., 2001. 18 с.

13. Nafie E., Mazen M. Chemical - Induced Resistance against Brown Stem Rot in Soybean: The Effect of Benzothiadiazole // Journal of Applied Sciences Research. 2008. Vol. 4(12). Pp. 2046-2064.

14. Рокицкий П.Ф. Биологическая статистика. Минск, 1973. 320 с.

15. Масленников П.В., Чупахина Г.Н., Скрыпник Л.Н., Федураев П.В., Мельник А.С. Оценка антиоксидантного потенциала растений урбоэкосистем в условиях антропогенного загрязнения почв // Экология. 2018. №5. C. $342-355$

16. Blokhina O., Virolainen E., Fagerstedt K.V. Antioxidants, Oxidative Damage and Oxygen Deprivation Stress: a Review // Annals of Botany. 2003. Vol. 91. Pp. 179-194. DOI: 10.1093/aob/mcf1 18.

17. Noctor G., Foyer C.H. Ascorbate and glutathione: keeping active oxygen under control // Annu. Rev. Plant Physiol. Plant Mol. Biol. 1998. Vol. 49. Pp. 249-279. DOI: 10.1146/annurev.arplant.49.1.249.

18. Загоскина Н.В. Фенольные соединения и их участие в защите растений от стрессовых воздействий // Фенольные соединения: Функциональная роль в растениях. М.: ИФР РАН, 2018. С. 150-153.

19. Valette N., Perrot T., Sormani R., Gelhaye E., Morel-Rouhier M. Antifungal activities of wood extractives // Fungal. Biol. Rev. 2017. Vol. 31. Pp. 113-123.

20. Peng W., Li D., Zhang M., Ge S., Mo B., Li S., Ohkoshi M. Characteristics of antibacterial molecular activities in poplar wood extractives // Saudi. J. Biol. Sci. 2017. Vol. 24. Pp. 399-404.

Поступила в редакичию 9 июля 2020 г.

После переработки 16 января 2020 г.

Принята к публикации 2 февраля 2021 г.

Для цитирования: Колтунов Е.В. Влияние стволовой гнили на фенольные соединения в листьях тополя бальзамического (Populus balsamifera L.) в условиях урбанизации // Химия растительного сырья. 2021. №2. С. $155-161$. DOI: 10.14258/jcprm. 2021028246. 
Koltunov E.V. INFLUENCE OF STEM ROT ON THE COMPOSITION AND THE CONTENT OF PHENOLIC COMPOUNDS IN THE LEAVES OF BOPLAMIC POPULUS (POPULUS BALSAMIFERA L.) UNDER THE CONDITIONS OF URBANIZATION

Botanical Garden of the Ural Branch of the Russian Academy of Sciences, ul. 8 Marta, 202a, Yekaterinburg, 620144, (Russia),e-mail: evg_koltunov@mail.ru

Balsam poplar is important component of landscaping urban environments. It's characterized by high growth rate and resistance to negative environmental factors, but in urbanization conditions it's intensely affected by diseases, especially stem rot. Biochemical composition of poplar has been studied, mainly in buds [1-4]. In leaves, it's less studied [5-7]. Therefore, study of influence of stem rot on phenolic compounds of Balsam poplar leaves at urbanization conditions was main purpose of research. Biochemical composition of leaves was studied by HPLC. Chromatography of leaf extracts revealed 88 compounds, identified 22 of them. Predominant tendency was activation of their synthesis: $45.46 \%$. Flavonoids are dominated in their composition (50\%). $27.27 \%$ of compounds inhibition of phenolic compounds synthesis was observed, $27.27 \%$ content is not change. This is consequence of reaction to oxidative stress. Differences in composition of chemical compounds in leaves of control and diseased plants were not observed. Reaction of woody plants different species to stem rot and pollution is different. This is due to both the species-specificity of the reaction and different levels of resistance and tolerance of various species and different mechanisms of adaptation to these factors. Probably different species of plants have different strategies for dealing with effects of environments factors, it's possible that similar mechanism exists for different species of stands affected by rot.

Keywords: HPLC, stem rot, balsamic poplar, leaves, phenolic compounds.

\section{References}

1. Isaeva E., Lozhkina G., Ryazanova T. Russian Journal of Bioorganic Chemistry, 2010, vol. 36 (7), pp. 929-933. DOI: $10.1134 / \mathrm{S} 1068162010070228$.

2. Isidorov V.A., Vinogorova V.T. Z. Naturforsch., 2003, pp. 355-360. DOI: 10.1515/znc-2003-5-612.

3. Isayeva Ye.V., Lozhkina G.A., Ryazanova T.V., Morozov S.V., Chernyak Ye.I. Khimiya rastitel'nogo syr'ya, 2008, no. 2, pp. 47-53. (in Russ.).

4. Zhanymkhanova P.Zh. Vestnik KGMA im. I.K. Akhunbayeva, 2015, no. 2, pp. 159-162. (in Russ.).

5. Isaeva E.V., Rjazanova T.V., Gavrilova L.V. Sciences of Europe, 2016, vol. 1, no. 8, pp. 116-121.

6. Isayeva Ye.V., Ryazanova T.V., Grak O.A. Novyye dostizheniya v khimii i khimicheskoy tekhnologii rastitel'nogo syr'ya: mate-rialy VII Vseros. konf. (24-28 aprelya 2017 g.). [New achievements in chemistry and chemical technology of plant raw materials: materials of the VII All-Russia. conf. (April 24-28, 2017)]. Barnaul, 2017, pp. 300-302. (in Russ.).

7. Sosipatrova A.A., Osipov V.I., Demina N.B., Bykov V.A. Voprosy biologicheskoy, meditsinskoy i farmatsevticheskoy khimii, 2011, no. 3, pp. 23-29. (in Russ.).

8. Shavnin S.A., Koltunov Ye.V., Yakovleva M.I. Sovremennyye problemy nauki i obrazovaniya, 2014, no. 6. URL: https://www.science-education.ru/ru/article/view?id=17151. (in Russ.).

9. Koltunov Ye.V. Uspekhi sovremennogo yestestvoznaniya, 2019, no. 9, pp. 19-25. (in Russ.).

10. Koltunov Ye.V., Yakovleva M.I. Sovremennyye problemy nauki i obrazovaniya, 2015, no. 5, URL: https://www.science-education.ru/ru/article/view?id=21797. (in Russ.).

11. Shavnin S.A., Koltunov Ye.V., Yakovleva M.I. Sovremennyye problemy nauki i obrazovaniya, 2014, no. 2, p. 520. (in Russ.).

12. Artemkina N.A. Nizkomolekulyarnyye fenol'nyye soyedineniya drevesnoy zeleni yeli yevropeyskoy (Picea abies L.). avtoref. dis. ... kand. khim. nauk. [Low molecular weight phenolic compounds of woody greens of European spruce (Picea abies L.). author. dis. ... Cand. chem. sciences]. St.-Petersburg, 2001, 18 p. (in Russ.).

13. Nafie E., Mazen M. Journal of Applied Sciences Research, 2008, vol. 4(12), pp. 2046-2064.

14. Rokitskiy P.F. Biologicheskaya statistika. [Biological statistics]. Minsk, 1973, 320 p. (in Russ.).

15. Maslennikov P.V., Chupakhina G.N., Skrypnik L.N., Fedurayev P.V., Mel'nik A.S. Ekologiya, 2018, no. 5, pp. $342-355$. (in Russ.).

16. Blokhina O., Virolainen E., Fagerstedt K.V. Annals of Botany, 2003, vol. 91, pp. 179-194. DOI: 10.1093/aob/mcf118.

17. Noctor G., Foyer C.H. Annu. Rev. Plant Physiol. Plant Mol. Biol., 1998, vol. 49, pp. 249-279. DOI: 10.1146/annurev.arplant.49.1.249.

18. Zagoskina N.V. Fenol'nyye soyedineniya: Funktsional'naya rol'v rasteniyakh. [Phenolic compounds: Functional role in plants]. Moscow, 2018, pp. 150-153. (in Russ.).

19. Valette N., Perrot T., Sormani R., Gelhaye E., Morel-Rouhier M. Fungal. Biol. Rev., 2017, vol. 31, pp. $113-123$.

20. Peng W., Li D., Zhang M., Ge S., Mo B., Li S., Ohkoshi M. Saudi. J. Biol. Sci., 2017, vol. 24, pp. 399-404.

Received July 9, 2020

Revised January 16, 2020

Accepted February 2, 2021

For citing: Koltunov E.V. Khimiya Rastitel'nogo Syr'ya, 2021, no. 2, pp. 155-161. (in Russ.). DOI: $10.14258 /$ jcprm. 2021028246 . 
